\title{
EMPREENDEDORISMO EM SITUAÇÃO DE POBREZA: REDUÇÃO DA POBREZA OU PERPETUAÇÃO DA POBREZA?
}

Daiane Martins Teixeira ${ }^{1}$

Daniel Do Prado Pagotto ${ }^{1}$

Ana Ysabel Urdaneta Xavier ${ }^{2}$

Karime Vitória Rodrigues Gouveia ${ }^{2}$

\footnotetext{
${ }^{1}$ Laboratório de Pesquisa em Empreendedorismo e Inovação (LAPEI-UFG) / Programa de Pós-Graduação em Administração / Universidade Federal de Goiás

${ }^{2}$ Universidade Federal de Goiás
} 


\section{EMPREENDEDORISMO EM SITUAÇÃO DE POBREZA: REDUÇÃO DA POBREZA OU PERPETUAÇÃO DA POBREZA?}

Resumo: O artigo trata-se de um ensaio teórico que possui o objetivo de realizar uma discussão sobre empreendedorismo em condições de pobreza, com base na literatura atual sobre temática. Por um lado, algumas pesquisas mostram que o empreendedorismo gera desenvolvimento, promovendo mudanças e crescimento estruturais que levarão à redução da pobreza e desigualdade. No entanto, outro grupo de estudos argumenta que o empreendedorismo em contexto de pobreza apenas reproduz um ciclo vicioso, no qual os empreendedores possuem claras desvantagens em relação a trabalhadores assalariados. Essas duas linhas de argumento sugerem que o empreendedorismo como redução da pobreza não apresenta resultados unânimes na literatura, o que instiga discussões como a do presente ensaio teórico.

Palavras-chave: Empreendedorismo. Pobreza. Exclusão social. Inclusão Social.

\section{$1 \quad$ Introdução}

De acordo com dados do Banco Mundial (2018), o número de pessoas que vivem abaixo da linha da pobreza é de 736 milhões no mundo, correspondente a cerca de $10 \%$ da população. No Brasil, essa realidade não é muito diferente, de acordo com dados do IBGE (2018), em 2017 cerca de aproximadamente 55 milhões de pessoas viviam com renda inferior a de $\mathrm{R} \$ 406,00$ mensais.

Entende-se que o fenômeno da pobreza tem natureza multidimensional, ao contrário do pressuposto de que está associado apenas à renda. Desse modo, compreende-se pobreza como uma condição na qual as necessidades dos indivíduos não são atendidas de maneira apropriada, como falta de acesso à renda, saúde, educação, segurança e infraestrutura básica (ROCHA, 2003; BANCO MUNDIAL, 2018). Com base nessa realidade, é nítido que há ainda locais que enfrentam a pobreza extrema e pesquisadores consideram que será o empreendedorismo uma das ferramentas viáveis para solucionar o combate à pobreza no mundo (SI et al., 2019; SUTTER; BRUTON; CHEN, 2019). Esse ponto de vista já era considerado em pesquisas anteriores, argumentando que seria a ação empreendedora o caminho necessário para gerar crescimento econômico e, consequentemente, desenvolvimento (SAUTET, 2013).

Nesse sentido, o empreendedorismo é visto como uma fonte de desenvolvimento, que promove mudanças e crescimento estruturais, além de ser uma opção de melhoria para pessoas que se encontram em situações de pobreza e desigualdade (NAUDÉ, 2010; CUMMING; JOHAN; UZUEGBUNAM, 2019).

Apesar de muito propagado, também existem estudos sobre empreendedorismo em contexto de pobreza que apresentam resultados opostos. Especificamente o trabalhador por conta própria, caracterizado como indivíduo com perspectivas limitadas de desenvolvimento (GINDLING; NEWHOUSE, 2014), que buscam alguma atividade laboral como opção para escapar do desemprego. Essa atitude, por sua vez, o conduz a criar negócios pautados na necessidade, os chamados empreendimentos de subsistência (KRASNIQI, 2014). E como 
consequência, o sistema social da pobreza gera a repetição desse padrão (ANDERSON; OBENG, 2017).

Percebe-se então que essa atividade pode ser um caminho propulsor para o fomento econômico, porém, quando se trata de locais mais pobres, esse atalho pode não ser o mais eficaz (LIN et al., 2019). Ou seja, empreender, principalmente em lugares com vulnerabilidade socioeconômica não é prerrogativa absoluta para gerar negócios produtivos e com capacidades de proporcionar desenvolvimento (SI et al., 2019).

Assim, o presente estudo tem por objetivo realizar uma discussão teórica que apresenta os dois lados do empreendedorismo no contexto de pobreza, a partir da literatura atual sobre o tema. Espera-se que este estudo possa contribuir para impulsionar um debate mais amplo e crítico sobre o papel do empreendedorismo em contextos de pobreza. Dessa forma, contribuindo para a formulação de políticas públicas direcionadas para essa realidade, realização de pesquisas futuras, orientação para organizações de apoio ao empreendedorismo e fundamentação para instituições de ensino.

A discussão está estruturada da seguinte forma: referencial teórico, dividido em três tópicos - Empreendedorismo em contexto de pobreza como gerador de inclusão social; Empreendedorismo em contexto de pobreza como perpetuador da exclusão social; Explicações para as diferentes evidências e argumentos e, após essa seção, encerra-se a discussão com a apresentação das considerações finais.

\section{$2 \quad$ Referencial Teórico}

A presente seção reúne estudos sobre empreendedorismo e sua relação com a pobreza. Assim, as subseções seguintes focam em, primeiramente, apresentar o que se compreende por pobreza nas pesquisas sobre empreendedorismo. Seguidamente, discutir estudos que defendem o empreendedorismo como uma saída para a pobreza e, em sequência, pesquisas que trazem o empreendedorismo nesse contexto como a reprodução de um ciclo de escassez. Por fim, são trazidas discussões que sustentam as diferenças nos resultados.

\subsection{O empreendedor em contexto de pobreza}

Conforme aponta Misturelli e Heffernan (2008), compreender a pobreza é fundamental dentro do conceito de desenvolvimento social. Khavul e Bruton (2013) sinalizam que tanto os fundamentos teóricos de como a pobreza surge, quanto o por que ela perdura são diversos e incertos. Isso permite entender que o seu conceito possui múltiplas faces, marcado por distintas abordagens na sua interpretação que engloba pontos de vistas que vão deste as questões sociais até questões econômicas (KOROSTELEVA; STĘPIEŃ-BAIG, 2019).

Por isso, para o presente estudo em que uns dos aspectos da discussão é pobreza, convém explicitar, especificamente, que o foco tratado no decorrer da discussão está direcionado a contextos em que pessoas sofrem sérias restrições (SI et al., 2019), como pouco crescimento econômico e desigualdades de recursos (GOEL; KARRI, 2019), o que certamente, as levam ao um limiar de subsistência (SI et al., 2019).

Seguindo por essa ótica, reduzir a pobreza tem sido pauta de discussão nos campos de pesquisas, dentre eles, encontra-se o empreendedorismo (SUTTER; BRUTON; CHEN, 2018). Isso certamente tem sido reflexo dos resultados de estudos que vêm mostrando o 
empreendedorismo como auxiliador para alcance de melhoria em comunidades pobres, contribuindo assim para a redução da pobreza (SI et al., 2019).

A esse respeito, as próprias pessoas dentro desses contextos são indivíduos capazes de desenvolver ações empreendedoras, desafiando as normas existentes e influenciando o ambiente institucional e cultural do local (GOEL; KARRI, 2019). Em contrapartida, essas pessoas que vivem em contextos de subsistência, normalmente são caracterizadas como indivíduos com baixo nível de escolaridade e que possuem baixo acesso a recursos (VISWANATHAN; SRIDHARAN; RITCHIE, 2010).

\subsection{Empreendedorismo em contexto de pobreza como gerador de inclusão social}

Há autores que defendem que empreender é um caminho para a prosperidade econômica, trazendo resultados como a criação de empregos, geração de renda, redução da pobreza, e, consequentemente, crescimento econômico. O novo modelo de produtividade introduzido por ações empreendedoras gera mudanças estruturais nas instituições e contexto da região (KAREEM, 2015; RIBEIRO-SORIANO, 2017).

De acordo com alguns teóricos, negócios criados em contexto de pobreza por vezes são marcados pela ineficiência e, por este motivo, deveriam ser evitados. No entanto, argumentos contrários defendem estes empreendedores, pois a ação deles os permite sair da pobreza e atender necessidades econômicas básicas. Além disso, eles possuem papel na conversão de recursos não produtivos em produtivos, uma vez que a experiência acumulada nessa categoria de negócio pode levar à criação de empreendimentos mais competitivos no futuro (MORRIS; NEUMEYER; KURATKO, 2015).

De acordo com estudo longitudinal nos EUA, observou-se que o primeiro o empreendedorismo gera redução do da pobreza, especialmente quando se trata da criação de negócios por oportunidades e que empregam outras pessoas (CUMMING; JOHAN; UZUEGBUNAM, 2019).

Si et al. (2019) ilustram o processo de redução de pobreza da cidade de Yiwu, na China, região marcada por pobreza extrema há trinta anos. De acordo com os autores, a redução da pobreza se deu a partir de um conjunto de fatores que emergiram ao longo do processo empreendedor. Primeiramente, devido às limitações produtivas do terreno, trabalhadores rurais foram forçados a comercializar produtos para sobreviverem. Devido à capacidade de compreensão da realidade local, os empreendedores conseguiram criar produtos mais aderentes à necessidade daquela comunidade. Além disso, aqueles indivíduos que haviam alcançado relativo sucesso contribuíram com os mais pobres, tanto por meio de ajuda mútua como também sendo modelos de referência de sucesso. Esse conjunto de elementos decorrentes da ação empreendedora permitiu a redução da pobreza na região.

Outro aspecto positivo trazido pela criação de empresas em contexto de pobreza, é a redução de conflitos. Em pesquisa realizada em Ruanda, país historicamente dividido em duas etnias (tutsi e hutus), Tobias, Mair e Barbosa-Leiker (2013) constataram que o empreendedorismo estimulou a cooperação entre os grupos para o alcance de objetivos econômicos. Isso, por sua vez, contribuiu para que os membros de um grupo vissem os demais de modo menos hostil, reduzindo, consequentemente, os conflitos entre os grupos. 
O quadro exposto abaixo apresenta de forma sintética resultados de estudos empíricos que defendem a participação do empreendedorismo como atividade promissora para contextos de extrema pobreza.

QUADRO 1 - Efeitos positivos do empreendedorismo em contextos de pobreza

\begin{tabular}{|c|c|c|c|}
\hline Autores & Objetivo & Contexto & Resultados \\
\hline $\begin{array}{l}\text { Bruton, } \\
\text { Ahlstrom e Si } \\
\text { (2015) }\end{array}$ & $\begin{array}{l}\text { Descobrir como a Ásia } \\
\text { lida com o combate à } \\
\text { pobreza por meio do } \\
\text { empreendedorismo. }\end{array}$ & $\begin{array}{l}\text { Utiliza de cinco } \\
\text { artigos científicos } \\
\text { pertinentes para a } \\
\text { discussão. }\end{array}$ & $\begin{array}{l}\text { Considera o empreendedorismo } \\
\text { um grande contribuinte para o } \\
\text { crescimento econômico e uma } \\
\text { ferramenta primária na } \\
\text { formulação de políticas } \\
\text { públicas }\end{array}$ \\
\hline $\begin{array}{l}\text { Brixiova e Égert } \\
\text { (2017) }\end{array}$ & $\begin{array}{l}\text { Examinar a influência } \\
\text { que outras instituições, } \\
\text { ambiente e habilidades } \\
\text { desempenham na criação } \\
\text { e desenvolvimento de } \\
\text { empreendimentos em } \\
\text { países com renda baixa. }\end{array}$ & $\begin{array}{l}\text { Usam conjunto de } \\
\text { dados } \\
\text { transversais } \\
\text { incluindo cerca } \\
\text { de } 100 \text { países. }\end{array}$ & $\begin{array}{l}\text { Instituições consistentes e } \\
\text { educação contribuem para a } \\
\text { criação de empresas de alta } \\
\text { produtividade e postos de } \\
\text { trabalho, sendo } \\
\text { complementares. }\end{array}$ \\
\hline $\begin{array}{l}\text { Lundy. } \\
\text { Patterson e } \\
\text { O'Neill (2018) }\end{array}$ & $\begin{array}{l}\text { Como as micro e } \\
\text { pequenas empresas em } \\
\text { um lugar } \\
\text { economicamente pobre } \\
\text { são capazes de se } \\
\text { desenvolver. Além disso, } \\
\text { descobrir se as micro e } \\
\text { pequenas empresas que } \\
\text { possuem estrangeiros } \\
\text { como donos são peças- } \\
\text { chaves para o } \\
\text { desenvolvimento } \\
\text { econômico neste } \\
\text { contexto. }\end{array}$ & $\begin{array}{l}\text { Pesquisa com } 153 \\
\text { empresas } \\
\text { instaladas em } \\
\text { Guiné-Bissau, } \\
\text { sendo } 82 \text { delas } \\
\text { estrangeiras. }\end{array}$ & $\begin{array}{l}\text { Apesar das restrições, como a } \\
\text { instabilidade política e a falta } \\
\text { de recursos, tanto os } \\
\text { empreendimentos locais quanto } \\
\text { os estrangeiros são importantes } \\
\text { no alívio da pobreza e possuem } \\
\text { a capacidade de transformar os } \\
\text { meios de subsistência em } \\
\text { motores do crescimento e } \\
\text { desenvolvimento econômico } \\
\text { em um local de baixa renda. }\end{array}$ \\
\hline $\begin{array}{l}\text { Cumming, } \\
\text { Johan e } \\
\text { Uzuegbunam } \\
\text { (2019) }\end{array}$ & $\begin{array}{l}\text { Examinar as relações } \\
\text { causais entre } \\
\text { desigualdade e } \\
\text { empreendedorismo por } \\
\text { meio da análise se a } \\
\text { desigualdade de renda } \\
\text { influencia na atividade } \\
\text { empreendedora e esta, } \\
\text { por sua vez, alivia a } \\
\text { pobreza extrema. }\end{array}$ & $\begin{array}{l}\text { Dados } \\
\text { quantitativos dos } \\
50 \text { estados dos } \\
\text { Estados Unidos } \\
\text { nos anos de } 1996 \\
\text { a } 2013 .\end{array}$ & $\begin{array}{l}\text { Fornece indícios que a } \\
\text { desigualdade de renda possui } \\
\text { capacidade de provocar a } \\
\text { atividade empreendedora, e a } \\
\text { atividade empreendedora } \\
\text { contribui para da redução da } \\
\text { pobreza absoluta. }\end{array}$ \\
\hline
\end{tabular}

Fonte: Elaborado pelos autores. 


\subsection{Empreendedorismo em contexto de pobreza como perpetuador da exclusão social}

Apesar de todos esses resultados positivos do empreendedorismo em situações de pobreza extrema, os efeitos da atividade nestes contextos são variados (ALVAREZ; BARNEY, 2014). O próprio contexto induz que o empreendedorismo em tais regiões seja focado apenas na sobrevivência (ANDERSON; OBENG, 2017), uma vez que se apresenta como a única saída de subsistência para pessoas que vivem em locais cujas condições lhe propiciam pouca probabilidade de inserção no mercado formal de trabalho (BUKSTEIN; GANDELMAN, 2014). Todavia, para entender se o empreendedorismo em contextos de pobreza perpetua a exclusão social, é necessário verificar a relação dos seus efeitos causados tanto no ambiente quanto no individuo empreendedor.

Uma pesquisa que buscou compreender a relação entre empreendedorismo e desigualdade de renda com dados anuais dos EUA, identificou que empreender é uma caminho propulsor para fomentar a desigualdade de renda e como consequência, essa desigualdade dificulta o crescimento econômico (ATEMS; SHAND, 2018). Outra pesquisa que analisou a função do empreendedorismo no crescimento econômico, utilizando como campo de análise 55 países, verificou que mesmo esse fenômeno sendo fundamental para o âmbito econômico, o seus efeitos positivos não podem ser generalizados, já que para países de baixa renda o seu efeito foi confirmado como negativo, enquanto para países de alta renda a relação é mais satisfatória (DORAN et al., 2018).

Investigando os processos empresariais de uma vila pobre em Gana, pesquisadores identificaram que os indivíduos situados nesse local são focados em desenvolver empreendimentos de subsistência, com a explicação de que o espaço social em que eles se encontram oferece poucas oportunidades de desenvolvimento e, como consequência desse fator, a própria pobreza torna-se uma reprodutora de si mesma (ANDERSON; OBENG, 2017).

Outro estudo em busca de entender a relação entre desigualdade e o empreendedorismo com pessoas da Índia constatou que há restrições para que uma pessoa torne-se um empreendedor, bem como, mostrou também que existe restrições na aquisição de recursos e desenvolvimento de atributos pessoais necessários para se tronar um empregador. Esses resultados significam que pessoas que lidam com a desigualdade tornam-se menos aptas para avançar dentro da atividade empreendedora, o que por sua vez, os restringem apenas a ocupações pautados na necessidade (SARKAR; RUFÍN; HAUGHTON, 2018).

Com a mesma perspectiva, Matos e Hall (2019) confirmam por meio de uma pesquisa realizada em uma comunidade pobre em João Pessoa, que mesmo muitas pessoas se envolvendo com o empreendedorismo nesse local, uma grande parcela não consegue desenvolver negócios produtivos. A explicação para isso, é que a miopia temporal, o entendimento errôneo de suas competências e o uso inadequado de seus contatos sociais contribuem para a criação de negócios mal sucedidos.

As considerações para isso é que o empreendedorismo, particularmente em contextos de extrema pobreza, nem sempre resulta em crescimento econômico (ALVAREZ; BARNEY, 2014) e melhorias de vida para pessoas que se aventuram nessa atividade (ANDERSON; OBENG, 2017).

A seguir, apresenta-se um quadro que reúne algumas das principais ideias dos autores que abordam o empreendedorismo e seus efeitos negativos em contextos de pobreza. 
QUADRO 2 - Efeitos negativos do empreendedorismo em contextos de pobreza

\begin{tabular}{|c|c|c|c|}
\hline Autores & Objetivo & Contexto & Resultados \\
\hline $\begin{array}{l}\text { Sarkar, Rufín e } \\
\text { Haughton } \\
\text { (2018) }\end{array}$ & 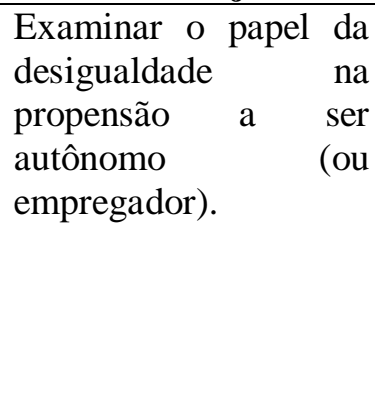 & $\begin{array}{l}\text { Dados da pesquisa } \\
\text { Socioeconômica das } \\
\text { famílias da Índia } \\
\text { entre julho de } 2011 \text { e } \\
\text { Junho de } 2012 .\end{array}$ & $\begin{array}{l}\text { Foi identificado indícios que } \\
\text { confirmam a existência de } \\
\text { limites para que o indivíduo } \\
\text { ultrapasse o limiar empresarial. } \\
\text { Isso ocorre devido a } \\
\text { desigualdade social que atua } \\
\text { como uma barreira, limitando o } \\
\text { crescimento dentro da atividade } \\
\text { empreendedora. }\end{array}$ \\
\hline $\begin{array}{l}\text { Atems e Shand } \\
(2018)\end{array}$ & $\begin{array}{l}\text { Estimar a relação entre } \\
\text { empreendedorismo e e } \\
\text { desigualdade de renda. }\end{array}$ & $\begin{array}{l}\text { Dados estaduais dos } \\
\text { EUA entre } 1989 \text { e } \\
\text { 2013. }\end{array}$ & $\begin{array}{l}\text { Os resultados confirmam uma } \\
\text { relação significativa entre } \\
\text { empreendedorismo } \\
\text { desigualdade de renda. Além } \\
\text { disso, constatam que políticas } \\
\text { voltadas ao fomento do } \\
\text { empreendedorismo aumenta a } \\
\text { desigualdade e retarda o } \\
\text { crescimento econômico. }\end{array}$ \\
\hline $\begin{array}{lll}\text { Matos } & \text { e } & \text { Hall } \\
(2019) & & \end{array}$ & $\begin{array}{l}\text { Explorar programas de } \\
\text { redução da pobreza no } \\
\text { Brasil } \\
\text { especificamente, } \\
\text { papel } \\
\text { empreendedorismo em } \\
\text { regiões pobres. }\end{array}$ & $\begin{array}{lr}\text { Comunidade } & \text { pobre } \\
\text { em João } & \text { Pessoa } \\
\text { (Brasil). } & \\
\end{array}$ & $\begin{array}{l}\text { Mesmo o empreendedorismo } \\
\text { sendo visto como caminho } \\
\text { propulsor para tirar pessoas da } \\
\text { pobreza, os negócios } \\
\text { desenvolvidos nesses contextos } \\
\text { tendem a ser improdutivos e } \\
\text { não alcançam o sucesso. }\end{array}$ \\
\hline Lin et al., (2019) & $\begin{array}{l}\text { Analisar } \\
\text { empiricamente } \\
\text { relação entre } \\
\text { empreendedorismo e } \\
\text { alívio da pobreza. }\end{array}$ & $\begin{array}{l}\text { Dados em painel de } \\
31 \text { províncias da } \\
\text { China entre } 2000 \text { e } \\
2017 \text {. }\end{array}$ & $\begin{array}{l}\text { A relação entre } \\
\text { empreendedorismo e redução } \\
\text { da pobreza é mais significativa } \\
\text { em áreas urbanas que nas áreas } \\
\text { rurais. Além disso, os seus } \\
\text { efeitos ecoam melhor em áreas } \\
\text { desenvolvidas quando } \\
\text { comparadas com áreas mais } \\
\text { carentes. }\end{array}$ \\
\hline
\end{tabular}

Fonte: Elaborado pelos autores.

\subsection{Explicações para as diferentes evidências e argumentos}

Reduzir a pobreza ainda é um ponto crítico, e não somente para formuladores de políticas públicas em todo o mundo, como também para pesquisadores que são instigados a buscar novas medidas para combater esse entrave (KOROSTELEVA; STĘPIEŃ-BAIG, 2019). Com base nessa realidade, o empreendedorismo ainda continua sendo apontado como ferramenta potencial para diminuição da pobreza (SI et al., 2019). Além disso, autores justificam que essa atenção ao empreendedorismo como gerador de crescimento e desenvolvimento aumentou devido à desaceleração do crescimento global e do comércio mundial (BRIXIOVA; ÉGERT, 2017). Outro ponto a ser mencionado, é que quanto maior é a 
proporção da desigualdade na sociedade, maior é o incentivo para o surgimento de mais empreendedores, sejam eles motivados pelo interesse próprio ou coletivo (CUMMING; JOHAN; UZUEGBUNAM, 2019).

Todavia, o empreendedorismo como promotor de desenvolvimento não é resultado unânime na literatura. As evidências apresentadas confirmam que o empreendedorismo não é sempre o propulsor de desenvolvimento de contextos com pobreza extrema (SI et al., 2019). Uma justificativa para isso é que as atividades empreendedoras mostram-se mais eficazes em países mais desenvolvidos, porém, em locais mais precários, o empreendedorismo não se mostrou como uma prática que produz resultados promissores (LIN et al., 2019). Isto pode estar atrelado ao fato de que nestes cenários, predomina o empreendedorismo por necessidade (DORAN et al., 2018), já que este se apresenta como alternativa viável para pessoas excluídas socialmente, que possuem baixa probabilidade de inserção no mercado de trabalho formal (BUKSTEIN; GANDELMAN, 2014).

De fato, a simples criação de empreendimentos no contexto de pobreza não é capaz de garantir crescimento econômico (DORAN et al., 2018). Por isso, é oportuno sugerir que a solução seja composta por uma abordagem mais holística, que atue sobre o suprimento de recursos limitados (ex.: recursos financeiros e conhecimento), bem como mudanças institucionais decorrentes da atuação de agências governamentais dispostas a incluir políticas que visam melhorias em áreas subdesenvolvidas, fortalecendo o empreendedorismo para que ele possa ser mais eficaz na diminuição da pobreza (LIN et al., 2019; SUTTER et al., 2019).

Há resultados que apontam que políticas e programas com a finalidade de incentivar o empreendedorismo não são suficientes para alcançar o crescimento (DORAN et al., 2018). Isso ocorre devido à baixa aderência das políticas públicas à realidade da pobreza. Há muitas iniciativas que buscam apenas emular o que se é aplicado em países desenvolvidos (SMITH et al., 2019). Desse modo, sugere-se que que políticas públicas de apoio à atividade empreendedora e ligadas à diminuição da pobreza sejam desenvolvidas em conjunto, visto que ambas se influenciam mutuamente (CUMMING; JOHAN; UZUEGBUNAM, 2019).

Doran et al., (2018) sugerem que as políticas públicas precisam transferir seu foco da quantidade de empreendedores para a qualidade dos empreendedores. Com iniciativas que garantam uma educação para o desenvolvimento de empreendimentos produtivos, com maiores chances de sobrevivência. Por outro ângulo, Atems e Shand (2018) concluíram que seria oportuno políticas que fomentem o crescimento econômico, ao invés de desenvolver políticas destinadas diretamente para criar empreendimentos.

Essas constatações impactam no incentivo ao microcrédito, pois, enquanto pesquisas apontam que o microfinanciamento é artificio potencial para reduzir a pobreza a nível global (COBB; WRY; ZHAO, 2016), por outro lado, na prática essa iniciativa nem sempre garante bons resultados (BHUIYAN; IVLEVS, 2019). Ou seja, proporcionar financiamento não garante retornos positivos, como o sucesso e crescimento econômico do local onde o empreendimento está inserido (LEE; DREVER, 2014).

Outra evidência pertinente é que mesmo as abordagens como auxílio externo, microfinanças e empreendedorismo social tendo sua contribuição para a eliminação da pobreza, nenhuma alcançou um resultado significativo no combate a essa adversidade. Indo mais além, a pesquisa ressalta que foi a industrialização a alternativa que obteve maior impacto, citando exemplos de países como China, Coréia do Sul e Índia. Portanto, segundo o 
estudo o mais viável seria políticas de industrialização para apoiar o desenvolvimento, já que as outras abordagens possuem efeito positivo temporário (ALVAREZ; BARNEY; NEWMAN, 2015).

Considerando outra explicação, é que em contextos de pobreza, o indivíduo pode estar preso em um sistema social com pouco espaço para empreender. Além disso, a estrutura social de pobreza é um elemento que como consequência, reproduz a pobreza (ANDERSON; OBENG, 2017). De fato, a desigualdade afeta o empreendedorismo, e como consequência altera a capacidade do indivíduo alcançar um limiar mais alto dentro dessa atividade (SARKAR; RUFÍN; HAUGHTON, 2018).

Por essa lógica, mesmo que haja necessidades de desenvolvimento de políticas públicas para fomentar a atividade empreendedora em contextos que se encontram na pobreza extrema, o ideal seria uma iniciativa que considerasse a cultura do local (ANDERSON; OBENG, 2017). Pois como sugerem Wassink (2018), investir em desenvolvimento social do local possui a capacidade de reduzir o empreendedorismo de subsistência, além de incentivar o trabalho formal e assim promover o empreendedorismo produtivo.

Outra descoberta interessante, é que existem distinções nas ações de intervenção em contextos pobres. Se o foco é fortalecer a resiliência, os meios de subsistência que fornecem renda, mesmo que pequena, para empreendedores serão o suficiente. Por outro lado, se o intuito é tirar indivíduos da pobreza, a sugestão é investir em mecanismos com potencial de gerar renda mais alta, mesmo que isso abranja uma menor quantidade de pessoas (TORELL et al., 2017).

Ademais, para que o empreendedorismo se torne um elemento capaz de combater a pobreza, é necessário compreender como a desigualdade afeta o desempenho empresarial (SARKAR; RUFÍN; HAUGHTON, 2018). Uma vez que pesquisas sobre esse fenômeno têm mostrado que enquanto o mesmo é caracterizado como fonte de maior mobilidade de renda para alguns, para outros têm sido fonte potencial de pobreza (HALVARSSON; KORPI; WENNBERG, 2018).

\section{Considerações finais}

Conforme declarado no início do presente estudo, o objetivo principal foi apresentar uma discussão teórica da bibliografia atual sobre o empreendedorismo e pobreza, com a tentativa de mostrar as duas perspectivas do empreendedorismo, ou seja, evidências que defendem o ator empreendedor e suas ações como o gerador de inclusão social, e resultados contrários que sustentam a ideia do empreendedorismo como reprodutor de desigualdades.

Nesse sentido, diferentes evidências aqui apresentadas mostraram que existe uma conexão inversa com redução da pobreza e empreendedorismo, ou seja, a lógica consistente que empreendedorismo pode sanar definitivamente a pobreza não foi sustentada (RAMBE; MOSWEUNYANE, 2017). Mesmo o empreendedorismo sendo um caminho para redução da pobreza, seus efeitos são mais predominantes em países desenvolvidos (LIN et al., 2019). Devese considerar também que lidar com contextos de pobreza, o fator desigualdade é um aspecto que impede que o indivíduo alcance avanços dentro dessa atividade, isso é reflexo de uma estrutura social que acaba atuando como um reprodutor da pobreza, gerando assim, empreendimentos mais pautados na subsistência.

Assim, o artigo traz contribuições por meio da discussão dos diferentes argumentos e dispõem de uma perspectiva crítica. Com isso, as evidências apresentadas merecem atenção, 
uma vez que a relação entre os aspectos empreendedorismo, pobreza e desigualdades são caracterizadas como complexas (CUMMING; JOHAN; UZUEGBUNAM, 2019).

Além do mais, como implicações práticas, as discussões geradas apresentam evidências que contribuem especificamente para formuladores de políticas públicas que buscam incentivar o empreendedorismo para o combate à pobreza, pois há uma necessidade de canalizar esforços mais assertivos, uma vez que desenvolver políticas para o fomento dessa atividade não garante retornos eficazes. A sugestão apresentada por Cumming, Johan e Uzuegbunam (2019) seria relacionar políticas públicas para a redução da pobreza com as que são destinadas para a encorajar ação empreendedora.

Por fim, tendo em vista a importância do tema, bem como o seu potencial de realização nas áreas, é importante a continuidade de estudos empíricos de viés crítico capaz de gerar observações interessantes para a melhor compreensão do tema. Para isso, considerando que o presente ensaio teórico não faz distinção entre trabalhadores por conta própria e empregadores, seria oportuno estudos que analisassem não somente as similaridades e diferenças dos mesmos, mas também o impacto deles como gerador de inclusão social ou exclusão social em situações de extrema pobreza.

\section{Referências}

ALVAREZ, S. A.; BARNEY, J. B. Entrepreneurial Opportunities and Poverty Alleviation. Entrepreneurship Theory and Practice, v. 38, n. 1, p. 159-184, jan. 2014.

ALVAREZ, S. A.; BARNEY, J. B.; NEWMAN, A. M. B. The poverty problem and the industrialization solution. Asia Pacific Journal of Management, v. 32, n. 1, p. 23-37, mar. 2015.

ANDERSON, A. R.; OBENG, B. A. Enterprise as socially situated in a rural poor fishing community. Journal of Rural Studies, v. 49, p. 23-31, jan. 2017.

ATEMS, B.; SHAND, G. An empirical analysis of the relationship between entrepreneurship and income inequality. Small Business Economics, v. 51, n. 4, p. 905-922, dez. 2018.

BHUIYAN, M. F.; IVLEVS, A. Micro-entrepreneurship and subjective well-being: Evidence from rural Bangladesh. Journal of Business Venturing, v. 34, n. 4, p. 625-645, jul. 2019.

BRIXIOVA, Z.; ÉGERT, B. Entrepreneurship, institutions and skills in low-income countries. Economic Modelling, v. 67, n. February, p. 381-391, dez. 2017.

BRUTON, G. D.; AHLSTROM, D.; SI, S. Entrepreneurship, poverty, and Asia: Moving beyond subsistence entrepreneurship. Asia Pacific Journal of Management, v. 32, n. 1, p. 122, mar. 2015.

BUKSTEIN, D.; GANDELMAN, N. Intra-generational social mobility and entrepreneurship in Uruguay. Latin American Journal of Economics, v. 51, n. 2, p. 227-245, dez. 2014.

COBB, J. A.; WRY, T.; ZHAO, E. Y. Funding Financial Inclusion: Institutional Logics and the Contextual Contingency of Funding for Microfinance Organizations. Academy of Management Journal, v. 59, n. 6, p. 2103-2131, dez. 2016.

CUMMING, D.; JOHAN, S.; UZUEGBUNAM, I. An anatomy of entrepreneurial pursuits in relation to poverty. Entrepreneurship \& Regional Development, v. 00, n. 00, p. 1-20, 2019. DORAN, J. et al. The role of entrepreneurship in stimulating economic growth in developed and developing countries. Cogent Economics \& Finance, v. 6, n. 1, p. 1442093, jan. 2018. 
GINDLING, T. H.; NEWHOUSE, D. Self-Employment in the Developing World. World Development, v. 56, p. 313-331, 2014.

GOEL, S.; KARRI, R. Entrepreneurial aspirations and poverty reduction: the role of institutional context. Entrepreneurship \& Regional Development, v. 00, n. 00, p. 1-21, jul. 2019.

HALVARSSON, D.; KORPI, M.; WENNBERG, K. Entrepreneurship and income inequality. Journal of Economic Behavior \& Organization, v. 145, p. 275-293, jan. 2018.

INSTITUTO BRASILEIRO DE GEOGRAFIA E ESTATÍSTICA. Síntese de indicadores sociais: Uma análise das condições de vida da população brasileira 2018 [Synthesis of social index: An analysis of the living standars of the Brazilian population 2018]. [s.l: s.n.]. KAREEM, R. O. Impact of entrepreneurship on poverty alleviation. Journal of Business Administration and Education, v. 7, n. 1, 2015.

KHAVUL, S.; BRUTON, G. D. Harnessing Innovation for Change: Sustainability and Poverty in Developing Countries. Journal of Management Studies, v. 50, n. 2, p. 285-306, mar. 2013. KOROSTELEVA, J.; STĘPIEN'-BAIG, P. Climbing the poverty ladder: the role of entrepreneurship and gender in alleviating poverty in transition economies. Entrepreneurship \& Regional Development, v. 00, n. 00, p. 1-24, 2019.

KRASNIQI, B. A. Characteristics of self-employment: A refuge from unemployment or road to entrepreneurship. Small Enterprise Research, v. 21, n. 1, p. 33-53, jan. 2014.

LEE, N.; DREVER, E. Do SMEs in deprived areas find it harder to access finance? Evidence from the UK Small Business Survey. Entrepreneurship \& Regional Development, v. 26, n. 3-4, p. 337-356, mar. 2014.

LIN, S. et al. Regional determinants of poverty alleviation through entrepreneurship in China. Entrepreneurship \& Regional Development, v. 00, n. 00, p. 1-22, jul. 2019.

LUNDY, B. D.; PATTERSON, M.; O'NEILL, A. The impact of foreign-owned enterprises in low-income economies. Development in Practice, v. 28, n. 7, p. 943-951, out. 2018.

MATOS, S.; HALL, J. An exploratory study of entrepreneurs in impoverished communities: when institutional factors and individual characteristics result in non-productive entrepreneurship. Entrepreneurship \& Regional Development, v. 00, n. 00, p. 1-22, jul. 2019.

MISTURELLI, F.; HEFFERNAN, C. What is poverty? A diachronic exploration of the discourse on poverty from the 1970s to the 2000s. The European Journal of Development Research, v. 20, n. 4, p. 666-684, dez. 2008.

MORRIS, M. H.; NEUMEYER, X.; KURATKO, D. F. A portfolio perspective on entrepreneurship and economic development. Small Business Economics, v. 45, n. 4, p. 713 $728,2015$.

NAUDÉ, W. Entrepreneurship, developing countries, and development economics: new approaches and insights. Small Business Economics, v. 34, n. 1, p. 1-12, jan. 2010.

RAMBE, P.; MOSWEUNYANE, L. A poverty-reduction oriented perspective to small business development in South Africa: A human capabilities approach. African Journal of Science, Technology, Innovation and Development, v. 9, n. 3, p. 289-302, maio 2017.

RIBEIRO-SORIANO, D. Small business and entrepreneurship: their role in economic and social development. Entrepreneurship \& Regional Development. v. 29: pp: 1-3, 2017 DOI: 10.1080/08985626.2016.1255438 
ROCHA, Sonia. Pobreza no Brasil: afinal, de que se trata?: afinal, de que se trata?. FGV Editora, 2003.

SARKAR, S.; RUFÍN, C.; HAUGHTON, J. Inequality and entrepreneurial thresholds. Journal of Business Venturing, v. 33, n. 3, p. 278-295, maio 2018.

SAUTET, F. Local and Systemic Entrepreneurship: Solving the Puzzle of Entrepreneurship and Economic Development. Entrepreneurship Theory and Practice, v. 37, n. 2, p. 387-402, mar. 2013.

SI, S. et al. Business, Entrepreneurship and Innovation Toward Poverty Reduction. Entrepreneurship \& Regional Development, v. 00, n. 00, p. 1-20, ago. 2019.

SMITH, A. M. J. et al. Poverty, social exclusion and enterprise policy : A study of UK policies ' effectiveness over 40 years. The International Journal of Entrepreneurship and Innovation, v. 20, n. 2, p. 107-118, 2019.

SUTTER, C.; BRUTON, G. D.; CHEN, J. Entrepreneurship as a solution to extreme poverty: A review and future research directions. Journal of Business Venturing, v. 34, n. 1, p. 197 $214,2018$.

T. WASSINK, J. Is Local Social Development Associated with Workforce Composition? A Municipal Analysis of Mexico, 1990-2015. Population Research and Policy Review, v. 37, n. 6, p. 941-966, dez. 2018.

THE WORLD BANK GROUP. The Poverty Puzzle Overview. Poverty and Shared Prosperity 2018. The World Bank Group. 2018.

TOBIAS, J. M.; MAIR, J.; BARBOSA-LEIKER, C. Toward a theory of transformative entrepreneuring: Poverty reduction and conflict resolution in Rwanda's entrepreneurial coffee sector. Journal of Business Venturing, v. 28, n. 6, p. 728-742, nov. 2013.

TORELL, E. et al. Coastal Livelihood Diversification as a Pathway Out of Poverty and Vulnerability: Experiences from Tanzania. Coastal Management, v. 45, n. 3, p. 199-218, maio 2017.

VISWANATHAN, M.; SRIDHARAN, S.; RITCHIE, R. Understanding consumption and entrepreneurship in subsistence marketplaces. Journal of Business Research, v. 63, n. 6, p. 570-581, jun. 2010. 